\title{
Nutritional assessment of two famine prone Ethiopian communities
}

Department of Community Health, Addis Ababa University, PO Box 6728, Addis Ababa, Ethiopia T Alemu

\section{Centre for}

International Health, University of Bergen, Norway B Lindtjørn

Correspondence to: Dr T Alemu.

Accepted for publication October 1996

\author{
Tadesse Alemu, Bernt Lindtjørn
}

international standards as the extent of genetic influence upon growth is not well described. ${ }^{5}$

Among children, malnutrition is associated with increased risk of sickness and death. ${ }^{6} \mathrm{Al}-$ though less is known about the consequences of malnutrition among adults, small body size is associated with reduced ability for work. ${ }^{7}$ For people living under marginal environmental conditions, the ability to survive sustained energy stress is often a question of how they adapt to marginal food availability. Because food insecurity affects the whole population, studying the state of nutrition of the communities as a whole is justified. This is important in labour dependent subsistence farming communities, in particular where drought and social unrest often result in food shortage and malnutrition. The issue of health and nutrition is thus not only of academic interest but also operationally of great social relevance.

The aims of this study are to describe the nutritional status of all age groups in two rural communities in Ethiopia and to compare two widely used international anthropometric references to measure malnutrition in different ethnic groups.

\section{Methods}

STUDY AREA AND POPULATION

This study is part of an investigation on the associations between health and nutrition in famine prone areas of Ethiopia. Our two study communities are Elka na Mataramofa farmers' association (Elka) in the Rift Valley and Punjido in Gambella (fig 1). Both subsistence farming communities have repeatedly been affected by drought and famine.

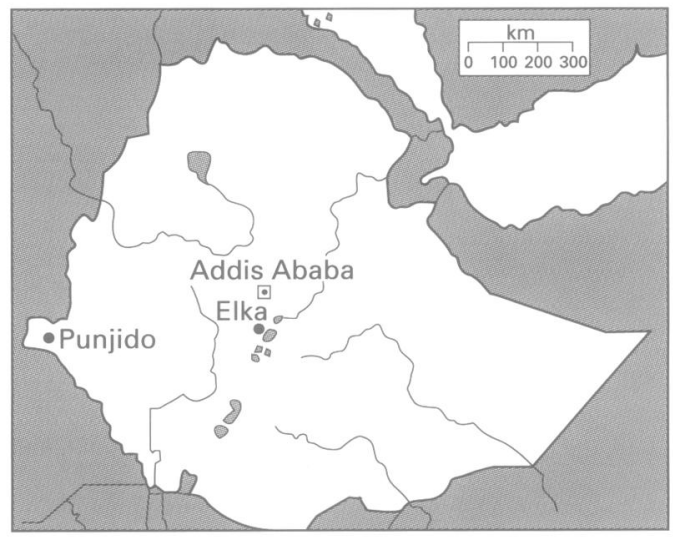

Figure 1 Map of Ethiopia with the two study areas Elka and Punjido.
Ethiopia experienced more devastating famines in the 1970 s and 1980 s than any other country in the world. ${ }^{1}$ In many communities, anthropometric measurements were compared to international references to assess the state of nutrition in individuals or in affected communities. ${ }^{2}$

Apart from a few ethnic groups, the growth of well nourished children with different ethnic background is similar ${ }^{3}$ and socioeconomic differences may influence growth more than genetic factors. ${ }^{4}$ However, if reliable local references are available, they may be preferred to

\begin{abstract}
different must be taken when assessing
\end{abstract}
(f Epidemiol Community Health 1997;51:278-282) 
Table 1 Age and sex distribution of the study populations

\begin{tabular}{lrllll}
\hline Age $(y)$ & Elka & & \multicolumn{2}{c}{ Punjido } \\
\cline { 2 - 3 } \cline { 5 - 6 } \cline { 5 - 6 } & No & Male:female & & No & Male:female \\
\hline $0-4$ & 235 & 0.94 & & 126 & 1.74 \\
$5-9$ & 243 & 0.91 & 92 & 1.09 \\
$10-14$ & 167 & 1.42 & & 80 & 0.91 \\
$15-19$ & 80 & 1.35 & & 51 & 0.50 \\
$20-29$ & 156 & 0.56 & & 58 & 0.57 \\
$30-39$ & 122 & 0.67 & & 55 & 0.34 \\
$40-49$ & 77 & 1.02 & & 41 & 0.24 \\
$50-59$ & 47 & 0.57 & & 31 & 0.48 \\
$>60$ & 43 & 1.39 & & 26 & 0.73 \\
Total & 1170 & 0.92 & 560 & 0.79
\end{tabular}

Elka is located $150 \mathrm{~km}$ south of Addis Ababa, and is inhabited mainly by the Arsi Oromo. It represents one large village and had, according to the 1989 census, 271 households and a population of 1382 . Punjido is a village in the lowland of west Ethiopia close to the Sudanese border. It is inhabited by the Anyuaks of the Luo-group of the Western Nilotes and had, in 1985,136 households with a population of 701.

The age and sex distribution of both communities (table 1) is typical of rural Ethiopia. ${ }^{8}$ However, a marked difference in the male to female ratio was observed in the age groups 20-39 for both communities. The difference is mainly explained by the military conscription that took place at the time. Thus, an estimated $15.3 \%$ and $20.1 \%$ of the population in Elka and Punjido respectively, were missing. Available for the anthropometric measurements were 1170 persons in Elka and 560 in Punjido.

In the Rift Valley farming is dependent on sufficient rainfall, as usually this part of the country is dry for most part of the year. On the other hand, regular farming in Punjido has been affected by the war between the Sudanese People's Liberation Movement and the Sudanese Government. Because of this unrest forced population movement in the area often occurs and has created food insecurity. ${ }^{9}$

\section{SOCIOECONOMIC, DEMOGRAPHIC, AND}

ENVIRONMENTAL DATA

Data on selected demographic, socioeconomic, and environmental variables were collected by enumerators using precoded questionnaires (table 2). In Elka the information was collected by enumerators who had completed 12 years of formal education, and in Punjido the same

\section{KEY POINTS}

- Anthropometric measurements are useful for assessing the state of nutrition in famine prone communities.

- The BMI may not be directly comparable when assessing populations with different genetic backgrounds.

- Care is needed when using existing international anthropometric references to compare different ethnic groups.

- Countries should establish anthropometric references for each of the major ethnic clusters.
Table 2 Socioeconomic characteristics of the study populations

\begin{tabular}{lrc}
\hline & Elka & Punjido \\
\hline Number: & 271 & 126 \\
$\begin{array}{l}\text { Household } \\
\text { Population }\end{array}$ & 1382 & 701 \\
$\begin{array}{l}\text { Person/household } \\
\text { Ethnicity (\%): }\end{array}$ & 5.1 & 5.3 \\
Arsi & 94 & \\
Kambata/Hadiya & 6 & \\
Anyuaks & 100 & \\
$\begin{array}{l}\text { Religion (\%): } \\
\text { Christian }\end{array}$ & 6 & 1 \\
Muslim & 94 & 99 \\
Traditional & & \\
$\begin{array}{l}\text { Occupation (\%): } \\
\text { Farming }\end{array}$ & 100 & 77 \\
Civil servant & & 11 \\
Other & & 12 \\
Housing (\%): & & 100 \\
Traditional hut & & \\
Corrugated iron roof & 3 & \\
\hline & &
\end{tabular}

information was obtained by final year medical students. All enumerators were trained in preparation for the work, and were regularly supervised. The recording procedures were controlled at random. Heads of household were interviewed about socioeconomic conditions, food availability, feeding habits. Mothers of children under 5 years were interviewed on breast feeding practice.

\section{ANTHROPOMETRY}

Anthropometric measurements were carried out in Elka in December 1989, and in Punjido in July 1985. Standardised procedures were used to measure weight, height, mid-upper arm circumference (MUAC) and triceps skin fold thickness (TSF). ${ }^{4}$

All anthropometric measurements were done at a central location in the villages. Instruments were regularly calibrated and the same person (Tadesse Alemu) did the anthropometric measurements throughout the study at both sites. The same length-board for infants was used on all length measurements and a height scale attached to a beam balance was used for older children and adults. Children under $25 \mathrm{~kg}$ were weighed to the nearest $100 \mathrm{~g}$ by using $25 \mathrm{~kg}$ Salter hanging scales and a standard beam scale was used for heavier children and adults. All weighing scales were centred at zero at the start of each session.

As birth date registration is uncommon in Ethiopia, age estimation was done using local calendar and events. ${ }^{4}$

Due to the absence of a local standard, international references were used to compare the values of measurements. For the age group 0-18 years weight for age (W/A) and height for age $(\mathrm{H} / \mathrm{A})$ were compared with the references of the National Centre for Health Statistics (NCHS/WHO). ${ }^{10}$ For adults the body mass index (BMI), calculated as weight $(\mathrm{kg}) /$ height $(\mathrm{m})^{2}$, was used to assess nutritional status. Adults with a BMI of less than 18.5 were considered malnourished. ${ }^{11}$

The US NHANES reference was used as a reference for the MUAC and TSF values. ${ }^{4}$ For MUAC, adults with values less than $80 \%$ of the reference median $(25.1 \mathrm{~cm}$ for men and 
Table 3 Comparison between the two study populations with regard to adult mean height, weight, body mass index, arm circumference(MUAC), triceps skinfold and (TSF), arm muscle circumference (AMC)

\begin{tabular}{|c|c|c|c|c|c|c|}
\hline & & \multicolumn{2}{|c|}{ Elka } & \multicolumn{2}{|c|}{ Punjido } & \multirow{2}{*}{$\frac{A N O V A}{p}$} \\
\hline & & No & Mean (SD) & No & Mean $(S D)$ & \\
\hline \multirow[t]{2}{*}{ Height } & Male & 188 & $167.1(7.9)$ & 67 & $176.6(7.7)$ & $<0.001$ \\
\hline & Female & 268 & $154.9(6.3)$ & 149 & $165.9(6.4)$ & $<0.001$ \\
\hline \multirow[t]{2}{*}{ Weight } & Male & 188 & $55.7(6.5)$ & 67 & $57.7(8.8)$ & $=0.01$ \\
\hline & Female & 268 & $50.4(7.3)$ & 149 & $47.2(5.5)$ & $<0.001$ \\
\hline \multirow[t]{2}{*}{ BMI } & Male & 188 & $19.9(1.9)$ & 67 & $18.4(2.2)$ & $<0.001$ \\
\hline & Female & 268 & $21.0(2.6)$ & 149 & $17.1(1.7)$ & $<0.001$ \\
\hline \multirow[t]{2}{*}{ MUAC } & Male & 187 & $24.1(1.8)$ & 66 & $25.4(2.3)$ & $<0.001$ \\
\hline & Female & 268 & $24.4(2.6)$ & 149 & $23.2(1.9)$ & $<0.001$ \\
\hline \multirow[t]{2}{*}{ TSF } & Male & 188 & $5.5(2.1)$ & 67 & $5.1(1.2)$ & $=0.28$ \\
\hline & Female & 268 & $10.3(4.3)$ & 149 & $7.1(2.6)$ & $<0.001$ \\
\hline \multirow{2}{*}{ AMC } & Male & 187 & $22.4(1.8)$ & 66 & $23.8(2.1)$ & $<0.001$ \\
\hline & Female & 268 & $21.2(1.9)$ & 149 & 20.9 (1.9) & $=0.36$ \\
\hline
\end{tabular}

ANOVA test controlling for age.
Table 4 Regression analysis with body mass index as the dependent variable (see text)

\begin{tabular}{|c|c|c|c|c|}
\hline & Variable & Beta & $t$ & $p$ \\
\hline$A$ & $\begin{array}{l}\text { Upper arm circumference }(\mathrm{cm}) \text { : } \\
\text { Site }(\text { Punjido }=1 ; \text { Elka }=0) \\
\text { Sex (male }=1 ; \text { female }=0) \\
\text { Site:sex } \\
\text { Age (y) } \\
\text { Constant }\end{array}$ & $\begin{array}{r}0.56 \\
-0.54 \\
-0.17 \\
0.09 \\
0.01 \\
5.2\end{array}$ & $\begin{array}{l}22.5 \\
18.0 \\
6.0 \\
2.9 \\
0.05 \\
6.9\end{array}$ & $\begin{aligned}<0.001 \\
<0.001 \\
<0.001 \\
0.004 \\
0.95 \\
<0.001\end{aligned}$ \\
\hline$B$ & $\begin{array}{l}\mathrm{F} \\
\mathrm{R}^{2} \\
\mathrm{p} \\
\text { Arm muscle circumference }(\mathrm{cm}) \text { : } \\
\text { Site (Punjido }=1 ; \text { Elka }=0) \\
\text { Sex (male }=1 ; \text { female }=0) \\
\text { Site:sex } \\
\text { Age }(\mathrm{y}) \\
\text { Constant }\end{array}$ & $\begin{array}{r}0.48 \\
-0.66 \\
-0.34 \\
0.16 \\
-0.02 \\
7.9\end{array}$ & $\begin{array}{l}15.9 \\
19.6 \\
10.2 \\
4.3 \\
1.03 \\
8.8\end{array}$ & $\begin{aligned} 216.1 \\
0.62 \\
<0.001 \\
<0.001 \\
<0.001 \\
<0.001 \\
<0.001 \\
0.30 \\
<0.001\end{aligned}$ \\
\hline$C$ & $\begin{array}{l}\mathrm{F} \\
\mathrm{R}^{2} \\
\mathrm{p} \\
\text { Upper arm circumference }(\mathrm{cm})^{*} \text { : } \\
\text { Site (Punjido }=1 ; \text { Elka }=0) \\
\text { Sex (male }=1 ; \text { female }=0) \\
\text { Site:sex } \\
\text { Age }(\mathrm{y}) \\
\text { Constant }\end{array}$ & $\begin{array}{r}0.59 \\
-0.46 \\
-0.16 \\
0.09 \\
-0.01 \\
4.5\end{array}$ & $\begin{array}{l}22.8 \\
14.7 \\
5.3 \\
2.5 \\
0.03 \\
6.1\end{array}$ & $\begin{array}{l}140.7 \\
0.51 \\
<0.001 \\
<0.001 \\
<0.001 \\
<0.001 \\
0.01 \\
0.97 \\
<0.001\end{array}$ \\
\hline & $\begin{array}{l}F \\
R^{2} \\
p\end{array}$ & & & $\begin{array}{c}186.6 \\
0.58 \\
<0.001\end{array}$ \\
\hline
\end{tabular}

* After correction for seasonal influence on weight.

\section{Results}

SOCIAL ASPECTS

Both populations were predominantly farmers (table 2). Ninety four per cent of the Elka population were Muslims, while in Punjido $99 \%$ followed traditional belief. The mean household sizes were 5.1 and 5.3 respectively, for Elka and Punjido.

In Elka older children and adults of household members participated in domestic, farm and herding activities. In Punjido, the men did seasonal farming and occasional fishing. Women in both communities were mostly involved in domestic activities, which included preparation of food, and fetching water and firewood. Children helped in the domestic and farming activities in both villages. $1.29 \mathrm{~kg}$ for men and $1.39 \mathrm{~kg}$ for women. We subtracted these measures from the actual weights in Elka, calculated a hypothetical "season of scarcity" BMI for Elka and compared it to the BMI in Punjido.

\section{ANALYSIS OF DATA}

Data analysis and statistical evaluation were done by the SPSS/PC.$+^{14}$ The $\chi^{2}$ test and $t$ test were used as appropriate. Analysis of variance was used to assess if significant variations in the height, weight, and anthropometric indices occurred between the two sites (table 3). The relationship between BMI and other nutritional indices was examined visually by plotting BMI against MUAC and AMC for the two sexes and sites. The patterns were then described in three models using multiple regression equations (table 4 ).

As shown, product terms between the variables sex and site (SEX-SITE) were included in the models to assess whether differences in BMI by MUAC or AMC varied between men and women at the two sites. Probability levels of $<0.05$ were considered significant.

\section{FOOD HABITS}

The staple diet both in Elka and Punjido was similar and maize based. In Elka vegetables, legumes and animal products were seldom eaten as these were considered important cash sources. In Punjido groundnuts formed a part of the diet which also included fish and meat from wild animals.

The duration of breast feeding was 12-24 months and similar for both communities. Milk was unavailable in Punjido because cattle rearing was not practised. Fifty six per cent of Elka households ate from the same dish and in 34\% of the households children shared food plates. In Punjido men did not share food plates with either their wives or children. In both societies husbands were served first.

\section{NUTRITIONAL STATUS}

Children in Elka followed the -2SD H/A of the reference median, while children in Punjido followed the reference median (fig 2). Figure 2 also shows that children in Elka and Punjido 

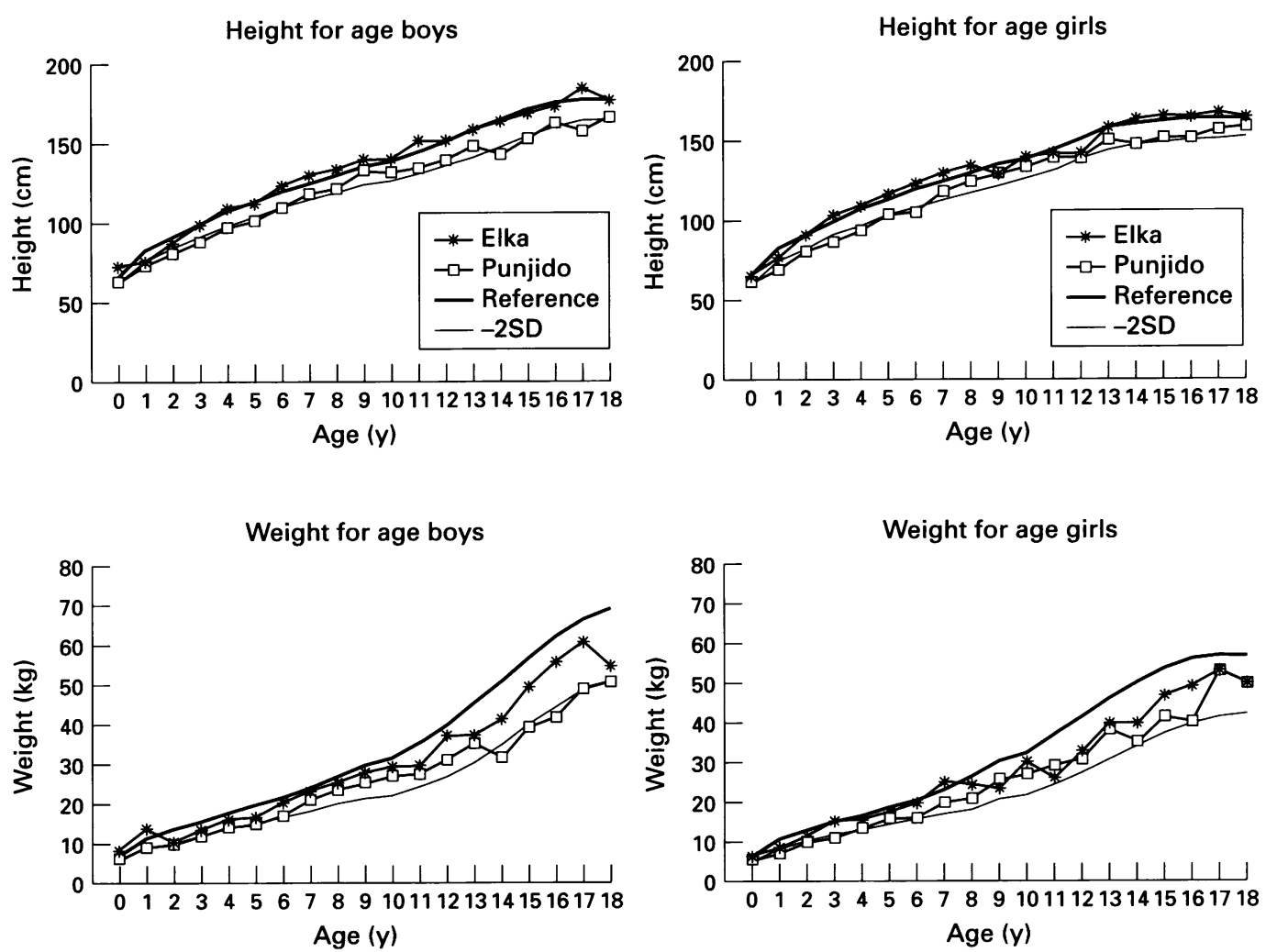

Figure 2 Height and weight for age for boys and girls in Elka and Punjido, Ethiopia.

had comparable weights, but lower mean values than -2 SD were observed for boys above 15 years of age in Elka.

Table 3, shows that men and women in Elka were shorter and men in Elka weighed less than the men in Punjido. However, both men and women had lower mean BMI in Punjido than in Elka, significantly so for the women. In Punjido men had higher mean BMI than the women $(t=4.31 ; \mathrm{p}<0.001)$ while the men in Elka had lower mean BMI than the women $(t=4.93 ; \mathrm{p}<0.001)$.

The mean TSF was low and corresponded in both communities to the 5 th centile of US NHANES reference for both males and females. Nevertheless, a significantly higher mean TSF was observed for the women in Elka than for the women in Punjido (table 3). The mean MUAC was at the level of $80 \%$ of the US NHANES reference median for both Elka and Punjido. The mean MUAC for men in Elka was significantly lower than that of Punjido, while the MUAC for women was significantly higher in Elka than in Punjido (table 3). Men in Punjido had a higher AMC than men in Elka. For women the AMC values were similar for Elka and Punjido (table 3).

Using the BMI to define malnutrition among the adults, $17.7 \%$ and $70.4 \%$ were malnourished in Elka and Punjido, respectively $\left(\chi^{2}=176.8 ; p<0.001\right)$. In Elka the prevalence of malnutrition was similar for men and women. In Punjido, more women $(79.2 \%)$ were malnourished than men $(50.7 \%)\left(\chi^{2}=\right.$ 16.6; $\mathrm{p}<0.001)$. On the other hand, using the MUAC to define malnutrition, $42.6 \%$ were malnourished in Elka compared to $37.2 \%$ in Punjido $\left(\chi^{2}=1.54 ; p=0.21\right)$. Our results show a considerable discrepancy in assessing prevalence of malnutrition using the $B M I$ and the MUAC $\left(\chi^{2}=30.8 ; \mathrm{p}<0.001\right)$. There was a significant association between $B M I$ and MUAC for Elka $(r=0.65 ; p<0.001)$ and for Punjido ( $\mathrm{r}=0.71 ; \mathrm{p}<0.001)$.

Table 4A shows that BMI was significantly associated with MUAC, sex, and site. As differences in subcutaneous fat, measured by the TSF, may partly explain the observed differences, we also compared the regression lines between BMI and AMC controlling for sex and site (table $4 B$ ). The regression analysis was repeated after correcting for possible seasonal weight changes (table $4 \mathrm{C}$ ). The results controlling for age, sex and the sex-site interaction show that the population in Punjido tended to have a lower BMI for the same AMC.

\section{Discussion}

This is the first description of the nutritional status of whole populations from two famine prone areas in Ethiopia. The two study populations represent typical communities in their respective regions. Using international references, a high prevalence of malnutrition was observed in both communities among all age groups. Among adults the number of malnourished as assessed by the BMI was significantly higher in Punjido than in Elka, but comparable rates were found when we used the MUAC to estimate the prevalence of malnutrition.

The greater heights of the Punjido as compared with the Elka may be caused by dietary difference, variance in disease pattern or genetic factors. In both communities the staple diet 
is based mainly on maize. Thus, children in Punjido were directly weaned to a maize based diet, whereas the children in Elka used milk during the weaning period. ${ }^{15}$ The food habits in our study population resemble those of the rest of Ethiopia, which show deficiencies in energy, protein, vitamins and minerals. ${ }^{16}$ The occurrence of childhood diseases such as diarrhoea and respiratory tract infections, known to affect child growth, are also similar $\left({ }^{17}\right.$ and Alemu T, 1985, unpublished data). The two populations also belong to different ethnic groups, and the tall and slim physical structure is known to be a characteristic of the Nilotic tribe to whom the Anyuaks belong. Therefore, genetic factors probably explain why the Anyuak in Punjido people are taller than the Arsi Oromo in Elka.

In Elka stunting starts at an early age. ${ }^{15}$ Although the study represents a cross sectional investigation, our data indicate that stunted children do not reach normal height as adults. Children in Punjido also live in an environment of chronic food shortage and experience moderate to heavy disease loads. Thus, the lack of appropriate anthropometric references for the Anyuaks in Punjido may hide the possible existence of stunting. The Samburu in Kenya and the Dinka from the Sudan are considered to be unusually tall ${ }^{11}$ and have low BMI, similar to our findings from the Anyuak in Punjido. Although seasonal and gender variations as well as socioeconomic difference may in part explain the observed difference in BMI between the two study populations, our results indicate that it is mainly the tall heights of the Anyuaks in Punjido that determine their low BMI values. Therefore, the low BMI among the Anyuaks is most probably a genetic feature.

Important differences between the Elka and Punjido populations were also observed when assessing the BMI together with the AMC. Men in Punjido had lower BMI but higher AMC than in Elka. Although women in Punjido had a much lower BMI than in Elka, their AMC were similar. Therefore, the BMI may not be directly comparable in our two study populations. Furthermore, if the AMC is a measure of muscle mass, ${ }^{4}$ and thus of working capacity, ${ }^{7}$ different references for the BMI may have to be applied to genetically different populations and local, appropriate references for each community may better define levels of malnutrition.

Recently, Flegal ${ }^{18}$ questioned the usefulness of the BMI for prevalence estimates of obesity across age, sex and ethnic groups. Our investigation shows it may be relevant to establish anthropometric references for each of the major ethnic clusters in countries such as Ethiopia. In particular, this is of practical importance when using anthropometry to assess the effect of famine among vulnerable populations. The study shows that care must be taken when assessing different ethnic groups using existing international anthropometric references.

Funding: this project was funded by the Norwegian Universities' Committee for Development Research and Education. Conflicts of interest: none.

1 Kloos H, Lindtiørn B. Famine and malnutrition. In: Kloos $\mathrm{H}$, Zein AZ, eds. The ecology of health and disease in $\mathrm{H}$, Zein AZ, eds. The ecology of health
Ethiopia. Boulder: Westview Press, 1993.

2 Lindtjorn B. Famine in southern Ethiopia 1985-86: Population structure, nutritional status and death among children. $B M \mathcal{F} 1990 ; 301: 1123-27$

3 Belew M, Jacobsson K, Tornell G, Uppsall L, Zaar B Vahlquist B. Anthropometric, clinical and biochemical studies in children from five different regions of Ethiopia. f Trop Pediatr 1972;18:229-77.

4 Jelliffe DB, Jelliffe EF. Community nutritional assessment. Oxford: Oxford University Press, 1989.

5 Waterlow JC. Protein energy malnutrition. London: Edward Arnold, 1992.

6 Tomkins AM. Protein-energy malnutrition and risk of infection. Proc Nutr Soc 1986;45:289-304.

7 Spurr GB. The impact of chronic undernutrition on physical work capacity and daily energy expenditure. Harrison GA, Waterlow JC, eds. Diet and disease in traditional and developing societies. Cambridge: Cambridge University developing societies.

8 Ethiopian Government. Ethiopia 1984, population $\mathbb{E}$ housing census preliminary report. Addis Ababa: Office of the population and housing census commission, 1984

9 Hailemariam A, Kloos H. Population. Kloos H, Zein AZ eds. The ecology of health and disease in Ethiopia. Boulder Westview Press, 1993:47-66.

10 WHO. Measuring change in nutritional status. Geneva: WHO, 1983.

11 James WP, Ferro-Luzzi A, Waterlow JC. Definition of chronic energy deficiency in adults. Eur $\mathcal{F}$ Clin Nutr 1988; 44:969-981.

12 Ferro LA, Scaccini C, Taffese S, Aberra B, Demeke T. Seasonal energy deficiency in Ethiopian rural women. Eur f Clin Nutr 1990;44(Suppl 1):7-18.

13 Alemu T, Lindtiørn B. Physical activity, illness and nutritional status among adults in a rural Ethiopian comtritional status among adults in a rural

14 Norusis MJ. SPSS/PC +. Base system user's guide. Version 5.0. Chicago: SPSS Inc, 1992.

15 Lindtjørn B, Alemu T, Bjorvatn B. Dietary pattern and state of nutrition among children in drought-prone areas in southern Ethiopia. Ann Trop Paediatr 1993;13:21-32.

16 Selinus R, Gobezie A, Knutsson KE, Vahlquist B. Dietary studies in Ethiopia: dietary pattern among the Rift Valley Arsi Galla. Am $\mathcal{F}$ Clin Nutr 1971;24:365-77.

17 Lindtjørn B, Alemu T, Bjorvatn B. Child health in arid areas of Ethiopia: Longitudinal study of the morbidity of infectious diseases. Scand F Infect Dis 1992;24:369-77.

18 Flegal KM. Defining obesity in children and adolescents: epidemiological approaches. Crit Rev Food Sci Nutr 1993; 33:307-12. 